\title{
Revisiting the orality-literacy relationship and its implications for English language teaching in Bangladesh
}

\author{
Md. Maksud Ali \\ Department of English Language \& Literature \\ International Islamic University Chittagong (IIUC), Bangladesh
}

\begin{abstract}
This paper focuses on different concepts of literacy and their implications for TESOL (Teaching English to Speakers of Other Languages). Taking a critical perspective, the study examines the traditional concept of literacy and illuminates how a narrow approach to literacy may lead to a conflict between national policy text and the actual pedagogic practices. Therefore, the author advocates for situating contemporary TESOL pedagogy within a broader concept. In addition, the study examines how literacy is embedded with orality, and whether the link between them has any implications for English language education in Bangladesh. It is argued here that since different cultures and societies do not adhere to a single set of literacy practices, an awareness of learners' and other stakeholders' socio-cultural concepts of literacy in a society is essential for TESOL practitioners in order for their materials and methods to be socio-culturally responsive. The study has implications for policy makers, materials writers and TESOL practitioners.
\end{abstract}

Keywords Literacy, Orality, TESOL, Socio-cultural background, Bangladesh

Paper type Review paper

\section{Introduction}

Literacy, as many will agree, has always been one of the much talked-about issues in educational discourse. However, the term itself is difficult to be defined easily. The conventional view of literacy is confined to reading and writing (Hopkins, 2009), thus, labelling those illiterate who cannot read or write (Jeffries, 1967). This conventional view separates the cultures which have rich socio-cultural tradition of orality with no tradition of written documentation from the cultures that have experienced reading and writing as the bases for literacy. The idea about literacy, however, has begun to change, and a broader view of literacy has emerged which holds

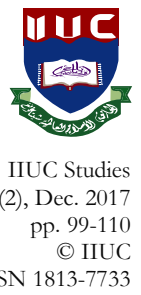


that literacy is a socially constructed functional ability, not just the reading and writing capacity (Cook-Gumperz, 2006).

This paper aims at exploring different concepts of literacy along with their implications for approaches to learning and teaching languages in general and for TESOL practices in particular. The study also focuses on the literacy-orality relationship and examines its implications for TESOL in Bangladesh. Finally, it is argues that second/foreign language teaching must consider learners' orality as a point of departure so that language learning is contextualised for the learners. It is also argued here that TESOL practitioners must be aware of learners' and other stakeholders' concepts of literacy within a society so as to avoid any mismatch between learning expectation and pedagogic practices in a given context.

\section{Literacy}

The traditional idea of literacy is so radical in nature that knowledge of the view is essential for language teachers to distinguish it from what is meant by literacy today. In the past, literacy was used to refer to the ability of reading and writing alone, and hence, treating those who could not do so as "illiterates" (Jeffries, 1967:3). Jeffries claims that in a "civilised society" reading and writing are "inseparable elements" and that the complete "social", "political" and "economic" base of a community depends on the ability of "every citizen" to communicate in written form. By claiming so Jeffries implicitly terms those who cannot read or write as not merely illiterate but he explicitly "classif[ies]" most adults of Asia, Africa and Latin America as also uncivilised since a significant portion of them cannot read and write (Jeffries, 1967:3). He further goes on to say that "visible symbols" are essential because "the want of such a symbol is itself the greatest impediment to the progress of civilisation....not only is such a symbol an essential element of civilisation, but it may be assumed as the very criterion of civilisation..." (Jeffries, 1967:4). In addition, for Jeffries (1967:15), symbol is very important because he thinks spoken words have no "permanence" and that they will die finally. However, these radical views may hurt those who can judge something properly although they cannot read or write. Cook-Gumperz (2006) suggests that most people view illiteracy as the lack of proper judgement, not just the inability to read or write. Besides, these extreme views separate the cultures which may be so prolific in oral tradition without any written document from the ones which view reading and writing as the bases of literacy. Can we really term the primitive people and even those in the present world who cannot read or write as illiterate or uncivilised? Therefore, a broader view of literacy is necessary. 


\section{Revisiting orality-literacy relationship 101}

The traditional view of literacy is also problematic as it fails to account for situations where oracies (i.e. spoken tradition) are more useful and functional than literacies (i.e., written tradition). Many young people in Bangladesh are an example: they can read and write Arabic but they cannot use the language in Arabian societies. On the other hand, most of them do not know a single letter of the Hindi alphabet, nor can they read and write in the language; yet, they are able to use the language in the social context. This has been possible for them as they have received numerous linguistic and functional stimuli in the language being exposed to the language in the media. Can we term them illiterate in Arabic or Hindi?

Indeed, literacy goes beyond what Cook-Gumperz (2006) terms "Western-centric view" which has failed to consider a myriad of diverse cultures across the world and which has misrepresented the notion of literacy for a long time. Cook-Gumperz defines literacy from what she calls an "ideological" point of view that literacy is a set of practices based on both the written and the oral tradition of languages. For Kern (2000), "...literacy is dynamic-not static-and variable across and within discourse communities and cultures" (p3). Therefore, a community may not have written documentation of its language, yet people in that community are communicating and performing their activities through their traditionally fostered oral languages. For example, some indigenous ethnic groups of people in Chittagong hill-tract area in Bangladesh until very recently did not have any written tradition of reading or writing. Although young children of some tribes are now having the blessing of formal education in their tribal languages, most aged people still do not know how to read or write. Nonetheless, they are performing their daily activities and rituals using their traditional oral languages that they have fostered for centuries. Hence, these people are civilised and literate in their own tradition inasmuch as they are able to perform their linguistic functions in their society using their oracies.

With the passage of time, the idea of literacy became even more sophisticated. It has already been indicated that literacy is not a one sided phenomenon, limiting itself merely to the ability of reading and writingindeed literacy is multi-faceted. It is interesting to note that Dubin (1989) speaks of "shopping literacy", "legal literacy", "geography literacy" etc. (Dubin, 1989:173). Literacy, in the present world includes what Stapleton (2005:135-136) calls "electronic literacy", which is important in the modern world on account of the massive shift from paper to the screen as a form of communication, even through electronic literacy does not need the ability to write. 
For Dubin (1989:172), "computer literacy has nothing to do with reading and writing. Rather, it means that an individual can cope with has the necessary know-how and skills to utilize - the computer in everyday activities". However, Hawisher and Selfe (2000:2) argue that "very little research has been conducted to trace culturally specific literacy practices online in ways that might offer additional perspective on the myth of a culturally neutral global network". They also claim "little or no work has been done to trace the ways in which specific, culturallydetermined literacy practices serve to constitute the web as a communication medium. Nor has there been significant and systematic study of cultural identities individuals create through their literary on the web" (Hawisher \& Selfe, 2000:2).

\section{What do the concepts mean for TESOL?}

The varying concepts of literacy have implications for TESOL. The traditional notion of literacy confines itself to reading and writing alone. Language teaching from this perspective is likely to take a traditional role in which focus is exclusively on reading and writing skills. This approach best fits within the Grammar Translation Method (GTM) - a method that aims to train learners in reading and writing skills so that they can understand and appreciate literature written in foreign languages. GTM, however, does not focus on functional aspects of a language as GTM ignores, in principle, to focus on listening and speaking skills of the target language. According to Larsen-Freeman (2000:16) within the scope of the GTM, "the ability to communicate in the target language is not a goal of foreign language instruction".

The broader view of literacy, on the other hand, focuses more on the functional aspects. Within this approach, TESOL is likely to take a comprehensive role in which focus should be placed not only on the development of reading and writing skills but also on the communication skills so that learners can use the English language in day-to-day glocal (global and local) settings. In other words, here TESOL education focuses on the four language skills - reading, writing, listening and speaking - so that learners can acquire the skills and use them in meaningful sociocultural, intercultural, employment, business, education, information transfer, etc. contexts. This approach takes a pragmatic view of languages, and it examines ways in which language teaching can be useful for the development of learners' communicative competence- "knowing when and how to say what to whom" (Larsen-Freeman, 2000:121). 


\section{Orality and literacy: The relationship}

Before we go further to explore the relationship between orality and literacy and their implications for TESOL, we need to be clear about what is meant by orality and oracy. Orality is the spoken tradition of a language (Ong, 2002). Oracy is the oral expression that people make through verbal elements of a language (Ong, 2002). However, how people speak (oracies) in a society is dependent on orality of that particular society. And the oral tradition of a community is deep-rooted in the past. This is true of literacy practices as well: Literacy cannot stand apart from the past. Barton, Hamilton and Ivanic (2000:13) maintain "...like all cultural phenomena, they [literacy practices] have their roots in the past. To understand the contemporary literacy it is necessary to document the ways in which literacy is historically situated...". This implies the relationship between the present literacies and the ancient ones. This is the point where orality and literacy meet. Cook-Gumperz (2006) claims literacy and orality cannot be opposite to each other. Literacy is somehow linked to the spoken world; reading something means transferring it to sound- aloud or in the imagination; thus "writing can never dispense with orality" (Ong, 2002:8). In addition, "writing does not reduce orality rather it organises the principles of oratory into scientific art..." (Ong, 2002:9). Orality of a culture can be termed the "Primary Orality" since it is "totally untouched by the knowledge of writing or print" while writing itself can be classified as "Secondary Orality" (Ong, 2002:11). What is important is that secondary orality is dependent on primary orality, which suggests that "orality of a language is permanent" (Ong, 2002:7).

\section{Implications of the relationship for TESOL}

The relationship between orality and literacy has ideological and pedagogical implications for TESOL. From an ideological point of view, TESOL policy makers, programme designers and materials writers need to consider learners' socio-cultural background and tradition (orality). In other words, one of the aims of TESOL teaching within ESOL contexts should be raising learners' awareness of their tradition, culture and customs that uphold their identity. Language teaching materials, in this case, need to make use of orality (that is rooted in learners' cultural heritage) in order to develop learners' literacy that is useful for them to function both in national and transnational contexts. Such an approach takes socio-cultural transformative agenda which cannot be implemented through a narrow concept of literacy which separates orality and oracy from literacy. 
From a pedagogical point of view, it is important that we focus on the four skills of the English language i.e., reading, writing, listening and speaking. This will be representative of both literacy and oracy and the broader aspect of literacy as discussed earlier. In addition, it is also important for language teachers to be aware of the socio-cultural concepts of literacies/oracies and orality of the learners. TESOL practitioners must know "...what literacy means to those who are acquiring and using it" (Goelman, Oberg, \& Smith, 1984:3) because "the concept of literacy has many implications [for many people]" (Goelman et al., 1984:21). Goelman et al. (1984), for example, reports on a study carried out by Schieffeling and Smith on the concept of literacy in three distinct groups: a group from a Philadelphic Suburb, another family from Papua New Guinea and the third group from a number of Chinese families settled in Philadelphia. The first group views literacy as an "integral part", while the second group does not think of literacy as an important aspect for the lives of their children. Finally, the third group observes literacy as "a social process" which helps people to tackle "with a new set of tasks" (Goelman et al., 1984:4-21).

Another implication is that TESOL education must be culturally responsive to a particular group. An example of "cultural responsiveness" in literacy education may be related to what a Jewish teacher says- "being Jewish, the concept of culturally responsive education gives me the idea of protection. I have seen discrimination around many times, and I know how it feels" (Porto, 2009:7). Porto (2009:9) puts forward that "ELT in the twenty-first century means culturally responsive literacy education" (p.1). Indeed, while teaching a foreign language, teachers need to make references to learners" "cultural" and "personal" identity so that they are able not only to learn another language but also to contribute to the "thoughts" and "principles" which their societies uphold (Mantero, 2003). For Porto (2009:2) "identity matters because it is an aspect of how humans make sense of the world and their experiences in it..." and also "identity matters because people can be understood by others in particular ways...".

Thus, TESOL literacy pedagogy should be what Cook-Gumperz (2006) terms ideological and it should not be, as Cope and Kalantzis (2000:9) suggest, restricted to "formalised", "monolingual", "monocultural" and "rule-governed form of language". Teachers must think about what kind of teaching is favourable to "women", "indigenous peoples", "immigrants" and to "speakers of non-standard dialect" (Cope \& Kalantzis, 2000:10). Therefore, in the classroom all the practices ought to be "culturally responsive" so that they become the "best practices" (Porto, 2009:3). Porto (2009) claims that when language teachers try to 


\section{Revisiting orality-literacy relationship 105}

understand the socio-cultural networks of the learners, there is a connection between what learners learn and how well they learn it (i.e., the content).

Language teachers' failure to understand learners' socio-cultural concept of literacies and oracies may impede learning and teaching. I experienced such an example at a language school in Bangladesh, where a native English speaking TESOL practitioner taught English for about four years. The lady never tried to understand how learners in Bangladesh acquire English as a foreign language. As a result, when any learner spoke or wrote English in the way he or she was socio-culturally built-up, the teacher readily rejected it, terming it to be 'Banglish'. It was rather interesting to note that she used to keep some mirrors with her and made the learners watch their own lips as they spoke. As a consequence, most learners lost the level of confidence they used to have in speaking. Hence, the approach the teacher took was not culturally responsive and the feedback she gave to the learners' performance in the target language (TL) as 'Banglish' was demotivating.

However, when learners' socio-cultural background and orality are taken into consideration, language learning itself becomes enjoyable. Nurss (2000) reports on a study that was conducted by Nurss and Rawlston in 1992 to demonstrate how learners' "cultural knowledge" has a positive impact on the learning of a target language. The aim of the project was to develop second language (L2) learners' oral English and English literacy by encouraging "folk-tale" and "oral tradition of storytelling" from the learners' own socio-cultural background. The participants included learners from Vietnamese, Laotian, Cambodian and Hispanic communities and their age ranged between two and 82. Aged participants from all the four different cultures were asked to find out a story from their own culture and explain it to other adults in English. The stories were composed by the tutor and later these were given to the adults. The adults revised them and finally typed them with the help of the older children who had computer operating skills. These activities gave the adults several "opportunities to practice reading the story aloud, reinforcing the English vocabulary and sentence structure, and explaining cultural concepts to the children". Eventually, the stories were compiled in a book with "audio tape recording" of the stories both in their first language (L1) and L2 (here, English). As a result, the learners, under investigation, could listen to the stories as they read them. As for the result of the project, the learners developed a positive attitude towards learning English as an L2. In particular, the approach helped them in vocabulary, forming concept, editing and comprehension strategies (For 
106 IIUC Studies, 14(2)

details, see Nurss, 2000:63-64). For a related case study see also Creese and Martin (2003).

\section{Pedagogical implications and recommendations for TESOL in Bangladesh}

Based on the arguments made through the above sections, a number of pedagogical implications may be drawn for English language teaching in Bangladesh. The Bangladesh government has recently adopted a communicative approach to the English language learning and teaching (National Educational Policy, 2010). In Bangladesh, development of communication skills in English is now seen critical for developing the citizens who will be able to participate in the global business and employment "from which they have previously been excluded" (Seargeant \& Erling, 2011:4). The shift towards a communicative approach to English language teaching has implications for the TESOL policy makers and practitioners in Bangladesh. Taking a narrow approach to literacy as a point of departure for syllabus and materials design as well as for pedagogy and assessment will directly contradict the national policy for developing communicative competence of the learners. In other words, we must find ways in which language teaching fits within the broader aspect of literacy which is contingent not only on the development of reading and writing skills but also on a number of other skills such as, listening and speaking skills, communication strategies and functional abilities in social contexts. Based on the critical perspectives made on literacy and the relationship between orality and literacy, the following implications and recommendations may be considered for TESOL practice in Bangladesh:

a. The current approaches to English language teaching in Bangladesh are to develop learners' communicative and functional skills so that they may have access to the globalised system (Ali, 2010; Ali \& Walker, 2014a; Ali, Hamid \& Hardy, 2018; Hamid \& Baldauf, 2008). Thus, language teaching with a traditional approach and method (e.g., the GTM) may not be appropriate to the goal of language teaching in the country. We need to situate TESOL in Bangladesh within a broader approach which takes into account not only the traditional literacies (i.e., reading and writing skills) but also the oracies (listening and speaking skills). This should be the case in all the stages of English language teaching, starting from the primary through the secondary to the tertiary level education. 


\section{Revisiting orality-literacy relationship 107}

b. Language teaching materials should make an extensive use of learners' orality (e.g., folklore and other stories available in oral tradition of Bangladesh). Learning tasks for literacy and oracy development may be based on those traditional stories or other national issues that are not beyond learners' cognitive domain. This essentially means that there should be an even representation of all cultural groups in Bangladesh. Generally, it is seen that some minority groups and their cultures (for example, the ethnic groups in hill-tract area in Chittagong or elsewhere) are less represented in the official textbooks (English for Today series) for TESOL education in Bangladesh (Ali, 2014). This should not be the case. The national curriculum may have a policy that can specify how cultural contents may be chosen and represented in the textbooks. However, materials writers need to be careful so as to avoid any cultural representation that is either biased or that may hurt any particular cultural or religious community.

c. With regards to the current TESOL goal of the country, language teaching materials can also sample contents for literacy and oracy tasks that are based on various socio-economic issues. Such materials can encourage learners to understand the process in which they may engage in and contribute to the socio-economic development of the country. However, the developmental agenda echoed in the educational policy and the national curricula are not truly reflected in the official textbooks (English for Today) inasmuch as the textbooks do not truly reflect the learners' and societal needs (Ali, 2014).

d. Teachers should be made aware of the current approaches to learning and teaching English in Bangladesh. They should be trained continuously so that they can make a connection between whom they teach and how they teach. This means teachers need to be helped in understanding the learning beliefs of a particular community or a particular age group. In other words, belief is an important issue that can impede learning and teaching. Every effort should be made so that there is congruence between how learners want to learn and how teachers teach.

e. Teachers also need to be trained in contextual pedagogy. Instead of sticking to a particular methodology (for example, Communicative Language teaching i.e., CLT), they can be encouraged to negotiate learning and teaching activities with those who are supposed to learn (i.e., the students). Such negotiation can be very useful as the process will create a scope for the teachers to make their practice culturally responsive to the people whom they teach. 
Overall, TESOL practices must be socio-culturally responsive. In the context of Bangladesh, this means that language teaching and learning need to be focused on the current national education policy of the country and the national curricula for primary and secondary education. Tertiary level education in Bangladesh also need to nurture the education policy and try to contribute to its goal- education for human capital development. We must examine ways in which English language teaching in universities may produce global citizens who will be equally sensible of their local and global responsibilities.

\section{Conclusion}

This paper has examined the traditional and the ideological concepts of literacy along with their implications for TESOL. The study has also focused on the orality-literacy relationship and the ways in which literacy education can be facilitated by including learners' orality. It has been argued here that apart from the ability to read and write, "socially constructed phenomenon" and "context-bound communicative practices" should also be considered to define literacy (Cook-Gumperz, 2006). Therefore, in stead of defining literacy in relation to a western-centric view, we have to consider the diversity of world's cultures. Thus, in teaching languages, for example, in teaching English to Speakers of Other Languages (TESOL), language teachers must be aware of the sociocultural concepts of literacies/oracies and orality of the learners so that the teachers can facilitate language pedagogy that is socio-culturally acceptable.

In conclusion, the study has a number of implications for TESOL in Bangladesh. First of all, language teaching in the country should be responsive to the national education policy and the national curricula for TESOL in the primary and the secondary education. The stakeholders must understand and work towards the implementation of the current approaches to learning and teaching English in Bangladesh i.e., development of communicative competence in English. What is important here is the need for an understanding of the fact that the current approaches to TESOL in Bangladesh cannot be anchored with the traditional concept of literacy as it is confined to reading and writing alone. The current goal, however, is to develop learners' functional skills for which essentially a broader understanding of literacy is needed as a theoretical framework for materials design, TESOL pedagogy and assessment. Secondly, materials writers should make use of the learners' orality in Bangladesh in order to design learning tasks for oracy and literacy development. This can help learners understand their identity 


\section{Revisiting orality-literacy relationship 109}

better and make use of it as they encounter other cultures (Ali \& Walker, 2014b). Finally, language teachers in Bangladesh should be trained in and made aware of the orality of various cultural groups in the country so that they can make use of it as they enter teaching profession.

\section{References}

Ali, M. M. (2010). Revisiting English language teaching (ELT) curriculum design: How appropriate is Bangladesh higher secondary level national ELT curriculum as a learner-centred one? IIUC Studies, 7, 283-296. http://dx.doi.org/10.3329/iiucs.v7i0.12494

Ali, M. M. (2014). An Evaluation of 'English for Today: for classes 11-12' as a Textbook for Bangladesh Higher Secondary Education (HSE). The English Teacher, $43(1)$, 1-18. https://journals.melta.org.my/index.php/tet/article/view/219/119

Ali, M. M., \& Walker, A. L. (2014a). 'Bogged down' ELT in Bangladesh: Problems and policy. English Today, 30(2), 33-38. doi:10.1017/S0266078414000108

Ali, M. M., \& Walker, A. L. (2014b). From home culture to intercultural knowledge base: Implications for TESOL materials design. Asian EFL Journal, 78, 27-36. https://www.asian-efl-journal.com/8395/teachingarticles/from-home-culture-to-intercultural-knowledge-base-implicationsfor-tesol-materials-design/

Ali, M. M., Hamid, M. O., \& Hardy, I. (2018). Ritualisation of testing: Problematising high-stakes English-language testing in Bangladesh. Compare: A Journal of Comparative and International Education, 1-21. DOI: 10.1080/03057925.2018.1535890

Barton, D., Hamilton, M., \& Ivanic, R. (2000). Situated literacies. London: Routledge.

Cook-Gumperz, J. (2006). The social construction of literacy. Cambridge: Cambridge University Press.

Cope, B., \& Kalantzis. M. (2000). Multiliteracies: Literacy learning and the design of social features. London: Routledge.

Creese, A., \& Martin, P. (2003). Multilingual classroom ecologies inter-relationships, interactions and ideologies. UK: Short Run Press Ltd.

Dubin, F. (1989). Situating literacy within traditions of communicative competence. Applied Linguistics, 10(2), 171-181. https://doi.org/10.1093/applin/10.2.171

Goelman, H., Oberg, A., \& Smith, F. (1984). Awakening to literacy. Oxford: Heinemann. 
Hamid, M. O., \& Baldauf, R. B. (2008). Will CLT bail out the bogged down ELT in Bangladesh? English Today, 24(3), 16-24. https://doi.org/10.1017/S0266078408000254

Hawisher, G. E., \& Selfe, C. L. (2000). Global literacies and the world-wide web. London: Routledge.

Hopkins, S. (2009). Orality, literacy, multiliteracies and K-12 education in BC. Available at: http://blogs.ubc.ca/etec540 sep09/2009/10/04/orality-literacymultiliteracy-and-k-12-education-in-b-c/

Jeffries, C. (1967). Illiteracy: a world of problem. London: Pall Mall Press.

Kern, R. (2000). Literacy and language teaching. Oxford: Oxford University Press.

Larsen-Freeman, D. (2000). Techniques and principles in language teaching (2 ${ }^{\text {nd }}$ ed.). Oxford: Oxford University Press.

Mantero, M. (2003). Second language literacy and communicative activity. Alabama: University of Alabama Press.

National Education Policy (2010). Bangladesh. Retrieved October 3, 2016, from https://old.moedu.gov.bd/index.php?option=com_content\&task=view\&id $=338 \&$ Itemid $=416$

Nurss, J. R. (2000). Intergenerational literacy: The use of story in family literacy instruction. ELT Journal, 362-368. https://doi.org/10.1093/elt/54.4.362

Ong, W. J. (2002). Orality and literacy: The technologizing of communicative competence. London: Routledge.

Porto, M. (2009). Culturally responsive L2 education: An awareness-raising proposal. ELT Journal, 64(1), 45-53. https://doi.org/10.1093/elt/ccp021.

Seargeant, P., \& Erling, E. J. (2011). The discourse of 'English as a language for international development': Policy assumptions and practical challenges. In H. Coleman, (Ed.), dreams and realities: developing countries and the English language (pp.248-267). London: British Council.

Stapleton, P. (2005). Evaluating web-sources: Internet literacy and L2 academic writing. ELT Journal, 59(2), 135-143. https://doi.org/10.1093/eltj/cci027

\section{Corresponding author}

Md. Maksud Ali can be contacted at: masud.np@gmail.com 